\title{
Insulin-Like Growth Factor-1 Contributes to Mucosal Repair by $\beta$-Arrestin2-Mediated Extracellular Signal-Related Kinase Signaling in Experimental Colitis
}

\author{
Tingting Chen, Fengping Zheng, Jin Tao, Siwei Tan, Lixian Zeng, Xiaojie Peng, and Bin Wu
}

From the Department of Gastroenterology, The Third Affiliated Hospital of Sun Yat-Sen University, Guangzhou, China

\author{
Accepted for publication \\ May 28, 2015. \\ Address correspondence to \\ Bin Wu, M.D., Ph.D., \\ Department of Gastroenter- \\ ology, The Third Affiliated \\ Hospital of Sun Yat-Sen \\ University, 600 Tianhe Rd., \\ Guangzhou 510630, China. \\ E-mail: wubin6@mail.sysu. \\ edu.cn or binwu001@hotmail. \\ com.
}

\begin{abstract}
Insulin-like growth factor-1 (IGF-1) possesses the ability to attenuate intestinal damage and promote mucosal repair of colitis. $\beta$-Arrestins, as the scaffolding proteins of $\mathrm{G}$ protein-coupled receptors or non- $\mathrm{G}$ protein-coupled receptors signaling, can be involved in IGF-1-mediated signaling pathways. However, the interaction of IGF-1 and $\beta$-arrestin2 in the mucosal repair of experimental colitis remains unexplored. Ulcerative colitis was induced in $\beta$-arrestin2 wild-type mice and $\beta$-arrestin2 knockout littermates by using $3 \%$ dextran sulfate sodium for 5 days, followed by regular water consumption for $1,2,3$, and 4 weeks to analyze the mucosal repair from experimental colitis. Disease activity index and histologic score analyses were performed. Apoptosis and proliferation were assessed by terminal deoxynucleotidy transferase-mediated dUTP nick-end labeling and Ki-67 staining, respectively. The expressions of $\beta$-arrestin2, phospho (p)-IGF-1R, and p-extracellular signal-regulated kinase (ERK)1/2 were examined. Furthermore, $\beta$-arrestin2 was overexpressed or altered in HCT116 cells by transfection before IGF-1 treatment in vitro. IGF-1 and $\beta$-arrestin2 expression was up-regulated in the repairing phase of experimental colitis. Targeted deletion of $\beta$-arrestin2 delayed the repair of colitis by inhibiting cell proliferation without affecting the levels of IGF-1 and p-IGF-1R. The $\beta$-arrestin2/ERK signaling pathway was involved in IGF-1-mediated mucosal repair through promoting epithelial cell and goblet cell regeneration from experimental colitis. These results indicate that IGF-1 contributes to the mucosal repair by $\beta$-arrestin2-mediated ERK signaling in experimental colitis. (Am J Pathol 2015, 185: 2441-2453; http://dx.doi.org/10.1016/j.ajpath.2015.05.020)
\end{abstract}

Ulcerative colitis (UC) is a type of inflammatory bowel disease (IBD), characterized by inflammation limited to the mucosal and submucosal layers of the colon. The cause of IBD involves a complex interaction among the genetic, environmental, and microbial factors and the immune responses. Although numerous theories have been proposed for the cause of $\mathrm{UC}^{1}{ }^{1}$ there has been less focus on the repair mechanism of colonic mucosa from UC. Thus far, the physiologic pathways involved in UC mucosal repair are only partially understood, and a growing body of evidence has found that the attainment of mucosal repair led to improved clinical outcomes and the promotion of the recovery of $\mathrm{UC}^{2}$ Here, we explored the definite mechanism of colonic mucosal repair to develop a novel approach for the treatment of UC.
$\beta$-Arrestins are scaffolding proteins that regulate $G$ protein-coupled receptor (GPCR) signaling and signal transduction. Of the four members of the $\beta$-arrestin family, $\beta$-arrestin 1 and $\beta$-arrestin 2 are ubiquitously distributed and originally identified as mediators of GPCRs desensitization and endocytosis. ${ }^{3}$ Emerging evidence has indicated that they are also scaffold components of numerous intracellular

\footnotetext{
Supported by the National Natural Science Foundation of China grant 81370511 (B.W.), the Science and Technology Planning Project of Guangdong Province grant S2012B060300014 (B.W.), and the Projects of Guangzhou City International Cooperation grant 2012J5100017 (B.W.).

T.C. and F.Z. contributed equally to this work.

Disclosures: None declared.
} 
signaling pathways, particularly those that involve mitogenactivated protein kinases (MAPKs), associated with cell growth, differentiation, proliferation, and apoptosis. ${ }^{4}$ Our partners have discovered that $\beta$-arrestin 2 contributes to the development of experimental colitis. ${ }^{5}$ In addition, we found that $\beta$-arrestin 2 was involved in the mucosal repair process of UC in a previous study (unpublished data).

Once damage occurs, the intestinal epithelium undergoes an injury-induced repair response to restore rapidly the structural and functional integrity. The efficient repair is accomplished by a process that consists of epithelial restitution, proliferation, and differentiation. ${ }^{6}$ After intestinal injury, progenitor cells proliferate and differentiate into mature epithelial cells to reestablish the epithelium. Studies have reported that a series of growth factors play important roles in this process. ${ }^{7-9}$ Insulin-like growth factor-1 (IGF-1), an important participant in tissue remodeling and repairing, has pleiotropic effects on cellular growth, differentiation, proliferation, and apoptosis. ${ }^{10-12}$ Most of the biological activities of IGF-1 are mediated by IGF-1 receptor (IGF-1R), through which extracellular signal-related kinase (ERK) signaling networks are also activated. ${ }^{13}$ The gastrointestinal tract is one of the main targets of IGF-1 action, and existing studies have indicated that exogenous IGF-1 could attenuate intestinal damage and promote mucosal repair. ${ }^{14-16}$ However, its definite mechanism in colonic mucosal repair is not completely understood.

The ability of $\beta$-arrestins to mediate MAPK signaling is not only mediated by GPCRs but also by non-GPCRs, and $\beta$-arrestins regulate the endocytosis and mitogenic signaling of IGF-1R. ${ }^{17-20}$ In addition, it was found that $\beta$-arrestins can bind to IGF-1R to promote its endocytosis and to enhance the downstream ERK signaling pathway. $\beta$-Arrestin-mediated ERK activation in the IGF-1/IGF-1R signaling pathway is always associated with cell growth and proliferation. On the basis of these findings, we explored the role of IGF-1 and IGF-1R signaling in the $\beta$-arrestin2-mediated ERK activation during the recovery phase of experimental colitis.

Here, we found that $\beta$-arrestin2 was up-regulated in response to IGF-1 during the recovery phase of dextran sulfate sodium (DSS)-induced experimental colitis. The targeted deletion of $\beta$-arrestin2 delayed the IGF-1-mediated mucosal repair in experimental colitis, and IGF-1 contributed to the mucosal repair of experimental colitis mainly by encouraging $\beta$-arrestin2-mediated ERK activation. These findings indicate a pivotal role of $\beta$-arrestin2 in the IGF-1-mediated mucosal repair of experimental colitis and provide sufficient scientific evidence to establish IGF-1 and $\beta$-arrestin2 signaling as a new therapeutic target of UC.

\section{Materials and Methods}

Mice

All procedures involving mice were approved by the Institutional Animal Care and Use Committee at the Sun Yat-Sen University. The original $\beta$-arrestin2 heterozygous mice in the
C57BL/6 background were a generous gift from Dr. Robert J. Lefkowitz (Duke University Medical Center, Durham, NC). The mice were kept in the animal house under $50 \%$ humidity and 12:12-hour light/dark cycles and were fed a standard pellet diet and tap water ad libitum, and 8- to 10-week-old mice were used for all experiments. PCR was performed to confirm the genotypes before the study. The presence of wild-type (WT) allele was detected with the forward primer 5'-GCTAAAGCGCATGCTCCAGA-3' and reverse primer $5^{\prime}$-ACAGGGTCCACTTTGTCCA-3' that produced a 1000-bp fragment. The mutant allele was detected with the forward primer 5'-GCTAAAGCGCATGCTCCAGA- $3^{\prime}$ and the same reverse primer for the WT allele to generate a 324-bp fragment.

\section{Induction of Experimental Colitis}

Mice were exposed to 3\% DSS (mol. wt., 36,000 to 50,000; MP Biomedical, LLC, Solon, OH) in the drinking water for 5 days, followed by water for 4 weeks. Control mice were allowed to drink only water at the same time. Mice receiving DSS for 5 days were used to analyze acute inflammatory damage. Mice exposed to DSS for 5 days were assessed mucosal repair from injury. General health condition, including body weight, stool consistency, and fecal bleeding, were recorded daily.

\section{Determination of the Disease Activity Index}

The disease activity index scores were determined daily during the experiment, as described previously. ${ }^{21}$ All scores were relative to the scores on day 1 , which were set as 0 . For body weight, no weight loss was scored as 0 , loss of $1 \%$ to $5 \%$ weight was registered as 1 , loss of $6 \%$ to $10 \%$ weight was registered as 2 , loss of $11 \%$ to $20 \%$ weight was registered as 3 , and loss of $>20 \%$ weight was registered as 4 . For stool consistency, 0 was scored for well-formed stool pellets, 2 was scored for pasty and semiformed stools that did not adhere to the anus, and 4 was scored for liquid stools that adhered to the anus. For bleeding, which was analyzed by the Hemoccult fecal occult blood test (Beckman Coulter, Brea, CA), 0 was assigned for no blood, 2 was assigned for positive Hemoccult test, and 4 was assigned for gross bleeding. All of the scores were confirmed in a blinded manner by two trained individuals (S.T. and L.Z.).

\section{Colonoscopic Assessment}

Mice were anesthetized and examined with a flexible fiberscope with a diameter of $2.8 \mathrm{~mm}$ (Olympus, Tokyo, Japan) assembled to a video camera to record images and to count ulceration. Colon injury was scored by two independent observers with the use of an adapted endoscopic index of colitis. ${ }^{22}$

\section{Sample Collection}

Mice were anesthetized by intraperitoneal injection of $10 \%$ chloral hydrate $(350 \mathrm{mg} / \mathrm{kg}$ body weight), and the colon was 
dissected. The colon was opened longitudinally and flushed with saline. For the histopathologic analysis, the entire colon was carefully rolled distal-to-proximal around a pipette tip and fixed immediately in 10\% formalin for 24 hours, then embedded in paraffin, and sectioned. To isolate the mucosa, the colon was scraped with a glass slide. The scraped samples were stored at $-80^{\circ} \mathrm{C}$ before extracting the proteins or RNA.

\section{Histologic Analysis and PAS Staining}

Tissue sections $(4 \mu \mathrm{m})$ of the colon were stained with hematoxylin and eosin for histologic analysis. Histologic scores were determined in a blinded manner (X.P.) on the basis of previously described criteria ${ }^{21}: 0$, normal; 1 , moderate mucosal inflammation without erosion or ulcer; 2, severe mucosal inflammation with erosion; 3, severe mucosal inflammation with ulcer $(<1 \mathrm{~mm}) ; 4$, severe mucosal inflammation with ulcer (1 to $3 \mathrm{~mm}$ ); 5 , severe mucosal inflammation with ulcer $(>3 \mathrm{~mm})$. To determine the numbers of ulcers, entire colons were collected from the treated mice and were fixed flat between wet filter paper pieces in $10 \%$ neutral buffered formalin for 48 hours. The tissues were stained with $0.2 \%$ methylene blue (SigmaAldrich, St. Louis, MO) in formalin solution for 5 minutes, and ulcerous areas were counted within 24 hours under a microscope. Periodic acid-Schiff (PAS) staining was performed according to the manufacturer's instructions (KeyGen Biotech, Nanjing, China) to quantify the number of goblet cells per crypt. Measurements for the quantitative outcome were collected from 100 crypts of each section.

\section{Immunohistochemical and IF Staining}

Standard immunohistochemical methods were used for the staining of various proteins. Paraffin-embedded colon sections were deparaffinized, rehydrated, and treated with $3 \%$ hydrogen peroxide, followed by antigen retrieval in boiling $0.1 \mathrm{~mol} / \mathrm{L}$ citrate $(\mathrm{pH} 6.0)$ buffer for 10 minutes. Sections were then blocked with $10 \%$ goat serum (Zymed, Carlsbad, $\mathrm{CA})$ and stained with antibodies against $\beta$-arrestin2 and $\beta$-arrestin1 (Abcam, Cambridge, MA); Ki-67 and proliferating cell nuclear antigen (PCNA; Santa Cruz Biotechnology, Inc., Santa Cruz, CA); phospho (p)-IGF-1R and p-ERK1/2 (Cell Signaling Technology, Danvers, MA); and cytokeratin (Santa Cruz Biotechnology, Inc.) respectively. For immunofluorescence (IF) staining, the targeted protein was detected by the related secondary antibody. Antibody-antigen complexes were visualized by incubation with biotin-conjugated secondary antibody and streptavidin Alexa 488 or 594 (Molecular Probes, Beijing, China), and the nuclei were counterstained with $2 \mathrm{mg} / \mathrm{mL}$ DAPI (Molecular Probes). For double staining, after completing the first protein detection, the slides were used to detect the secondary protein. The proliferative index was determined by the percentage of $\mathrm{Ki}-67^{+}$cells in the crypt, and 100 crypts were counted for each section. For cells for IF staining, the cells after the indicated treatment were immediately fixed in $4 \%$ paraformaldehyde before the abovementioned process. The proliferative index was calculated by counting a minimum of 20 randomly selected fields after PCNA IF staining. The index was obtained by dividing the $\mathrm{PCNA}^{+}$cells by the total number of cells.

\section{Apoptosis Assays}

Apoptotic cells were detected by terminal deoxynucleotidyl transferase-mediated dNTP nick-end labeling (TUNEL). TUNEL staining was performed with the ApopTag kit (Roche, Geneva, Switzerland) according to the manufacturer's instructions. TUNEL ${ }^{+}$cells were counted in a blinded fashion (S.T. and L.Z.) and were expressed as the number of apoptotic cells per 100 colonic crypts, as we have reported previously. ${ }^{21}$

\section{Real-Time PCR}

Total RNA was isolated and reverse transcribed with SuperScript III reverse transcriptase (Invitrogen, Carlsbad, CA) according to the manufacturer's instructions. The expression of IGF-1, transforming growth factor- $\beta$ (TGF- $\beta$ ), epidermal growth factor (EGF), and basic fibroblast growth factor (bFGF) mRNA were analyzed by real-time PCR performed with the Mini Opticon Real-Time PCR System (Bio-Rad, Hercules, CA) with SYBR Green (Invitrogen). The following primers were used: IGF-1 forward primer, 5'-TCATGTCGTCTTCACACCTCTTCT- $3^{\prime}$, and reverse primer, $5^{\prime}$-CCACACACGAACTGAAGAGCAT-3'; TGF- $\beta$ forward primer, 5'-GGACTCTCCACCTGCAAGAC-3', and reverse primer, 5'-GACTGGCGAGCCTTAGTTTG-3'; EGF forward primer, 5'-CGGACAGCTACACGGAATG- $3^{\prime}$, and reverse primer, 5'-CGAGGCAGACACAAATAACCC-3'; bFGF forward primer, $5^{\prime}$-GTCACGGAAATACTCCAGTTG-3' ${ }^{\prime}$, and reverse primer, 5'-CCGTTTTGGATCCGAGTTTATACT-3'.

\section{Cell Culture and Transfection}

HCT116 cells were grown in Dulbecco's modified Eagle's medium/F12 with $10 \%$ fetal bovine serum. Cultures were maintained at $37^{\circ} \mathrm{C}$ in a humidified atmosphere of $95 \%$ air and $5 \%$ carbon dioxide. $\beta$-Arrestin2 overexpression in HCT116 cells was induced. Plasmid encoding pcDNA3.0$\beta$-arrestin2-green fluorescent protein (GFP) was kindly provided by Professor Pei Gang (Tongji University, Shanghai, China). Cells were transfected with Lipofectamine 2000 (Invitrogen) according to the manufacturer's instructions. The construct that contained only the pcDNA3.0-GFP vector was also transfected as the control group. siRNA was introduced into cells according to the manufacturer's instructions (GenePharma, Shanghai, China). IGF-1 (100 ng/mL; Sigma-Aldrich) was added to cells on reaching $90 \%$ confluence. The specific ERK 
inhibitor PD98059 (20 $\mu \mathrm{mol} / \mathrm{L}$; Cell Signaling Technology) was added 1 hour before IGF-1 treatment.

\section{SDS-PAGE and Western Blot Analysis}

Proteins extracted from colonic mucosa and cell lysates were analyzed by SDS-PAGE. Separated proteins were transferred to nitrocellulose membranes, blocked at room temperature for 2 hours in Tris-buffered saline with $0.1 \%$ Tween 20 that contained 5\% skim milk, probed with primary antibodies at $4{ }^{\circ} \mathrm{C}$ overnight, and incubated with the appropriate peroxideconjugated secondary antibody. Finally, images were acquired with enhanced chemiluminescence detection in a darkroom. The following antibodies were used: $\beta$-arrestin1, $\beta$-arrestin2, p-IGF-1R, IGF-1R, p-ERK1/2, ERK1/2, and cleaved caspase-3 (all from Cell Signaling Technology), PCNA, $\beta$-actin, and glyceraldehyde-3-phosphate dehydrogenase (all from Santa Cruz Biotechnology, Inc.).

\section{Statistical Analysis}

Statistical comparisons were performed with SPSS 13.0 (SPSS Inc., Chicago, IL). All data are reported as means \pm SD. Comparisons of multiple groups were analyzed by a one-way analysis of variance, followed by the Bonferroni post-test. The differences between two groups were determined with $t$-test. $P<0.05$ was considered statistically significant.

\section{Results}

$\beta$-Arrestin2 Expression Is Up-Regulated During the Mucosal Repair of Experimental Colitis

In our previous study, we have reported that $\beta$-arrestin 2 is induced in UC, and increased expression of $\beta$-arrestin2 correlates with the severity of colitis. ${ }^{5}$ From this finding, we explored whether $\beta$-arrestin2 is also involved in the recovery phase of experimental colitis. Oral administration of DSS in mice induced acute experimental colitis that shared clinical and histopathologic characteristics with human UC, followed by a relatively slow mucosal repair. ${ }^{23,24}$ C57BL/6 mice were exposed to $3 \%$ DSS for 5 days to analyze acute inflammatory damage, and then they were switched to regular water for $1,2,3$, and 4 weeks to analyze the mucosal repair from injury. Real-time PCR data found that $\beta$ arrestin 1 was only induced during the acute phase but not in the recovery phase of colitis; however, $\beta$-arrestin 2 expression was significantly elevated not only during the acute phase but also in the recovery phase (Figure 1, A and B). Furthermore, Western blot analysis found that only the expression of $\beta$-arrestin2 but not $\beta$-arrestin1 was
A

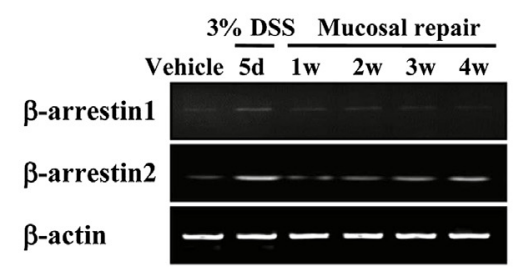

C

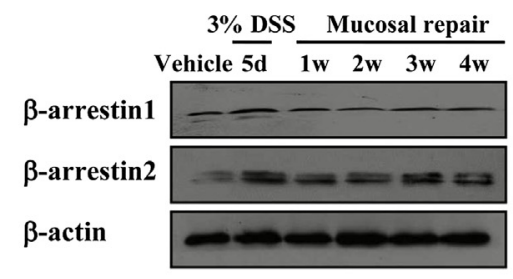

B

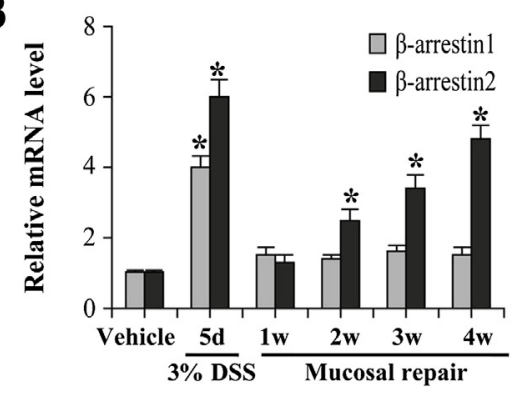

D

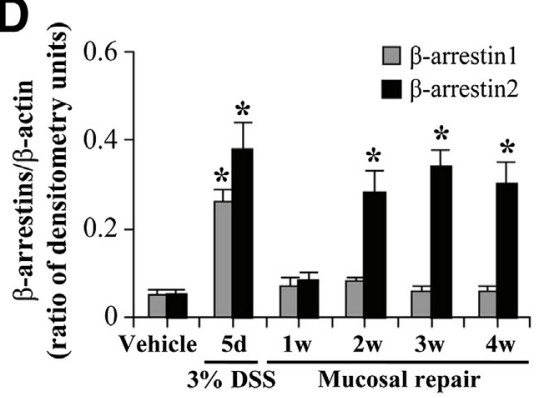

E

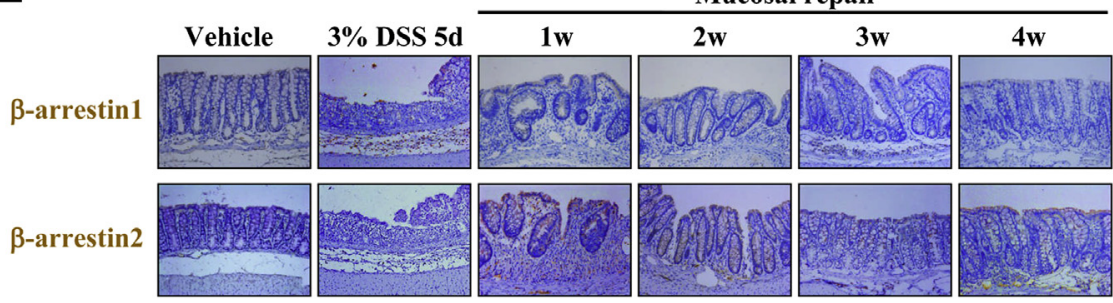

Figure $1 \quad \beta$-Arrestin2 expression is upregulated during the mucosal repair of experimental colitis. A: $\beta$-Arrestin1 and $\beta$-arrestin2 mRNA expression in the colonic mucosa were evaluated by real-time PCR at the indicated time points. B: Real-time PCR found relative $\beta$-arrestin1 and $\beta$-arrestin2 mRNA fold changes at the indicated time points. C: $\beta$-Arrestin1 and $\beta$-arrestin2 protein expression in the colonic mucosa were determin ed by Western blot analysis at the indicated time points. $\beta$-Actin was used as the loading control. $\mathbf{D}$ : The ratios of the densitometry units of $\beta$-arrestin1 $/ \beta$-actin and $\beta$-arrestin2 $\beta$-actin are represented. E: Immunohistochemical staining for $\beta$-arrestin1 and $\beta$-arrestin2 in the colonic sections of mice at the indicated time points (brown). Values are expressed as means \pm SD. $n=3$ in each group. ${ }^{*} P<0.05$ versus vehicle mice. Original magnification, $\times 200$. d, day; DSS, dextran sulfate sodium; w, week. 
significantly up-regulated during the recovery phase, although both proteins were induced in the acute phase (Figure 1, C and D). Immunohistologic staining revealed that the expression of $\beta$-arrestin1 was only up-regulated during the acute phase, whereas $\beta$-arrestin 2 protein was significantly elevated in both the acute and recovery phases (Figure 1E). Therefore, we concluded that $\beta$-arrestin2 expression was induced during the mucosal repair of experimental colitis and that $\beta$-arrestin2 played a distinct role in the recovery period of experimental colitis.

\section{$\beta$-Arrestin2 Deficiency Delays the Mucosal Repair of Experimental Colitis in Mice}

To further investigate the role of $\beta$-arrestin 2 in the recovery of experimental colitis, we compared the recovery process of DSS-induced experimental colitis between $\beta$-arrestin2 $\mathrm{WT}$ and $\beta$-arrestin2 knockout (KO) littermates in C57BL/6 background. $\beta$-Arrestin2 $\mathrm{KO}$ mice showed normal architecture of the colonic mucosa and no change in body weight or stools compared with $\beta$-arrestin2 WT mice. In response to DSS treatment, both genotypes of mice displayed features of colitis characterized by the loss of body weight, loose stools, and occult blood in the feces. Colonic mucosa experienced crypt destruction, goblet cell loss, and inflammatory cell infiltration. Coinciding with our previous research, ${ }^{5}$ targeted deletion of $\beta$-arrestin2 attenuated experimental colitis during the acute phase, as indicated by a reduction in the clinical and histologic scores in $\beta$-arrestin2 KO mice compared with WT mice (Figure 2, A and C). After removing DSS for 1 week, histopathologic analysis revealed colonic mucosal healing and epithelial reestablishment at the edge of injured mucosa in WT mice. By contrast, inflammation and crypt loss worsened progressively, and repair was initiated at 2 weeks after DSS withdrawal in $\beta$-arrestin2 KO mice. By 3 weeks of recovery, the mucosa regenerated to almost the normal state in WT mice as compared with 4 weeks in $\beta$-arrestin2 $\mathrm{KO}$ mice (Figure 2A). Scoring of histologic sections, disease activity index, and ulcer counting provided quantitative evidence
A

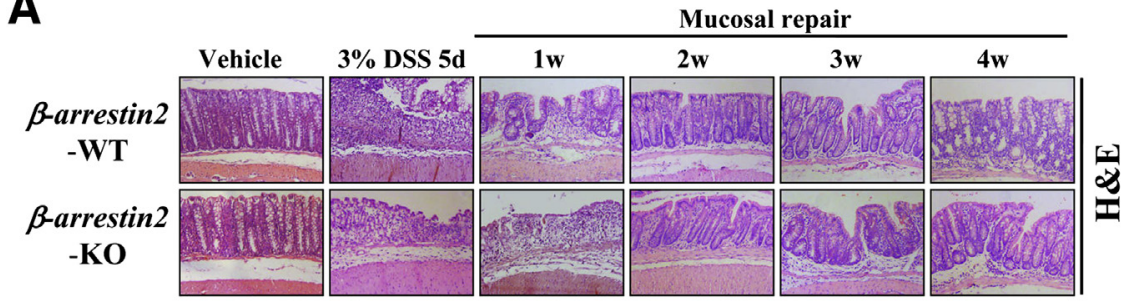

B

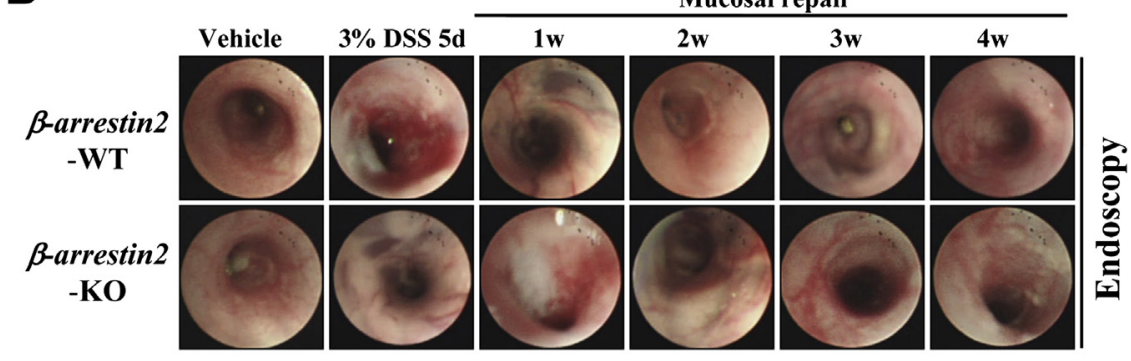

C

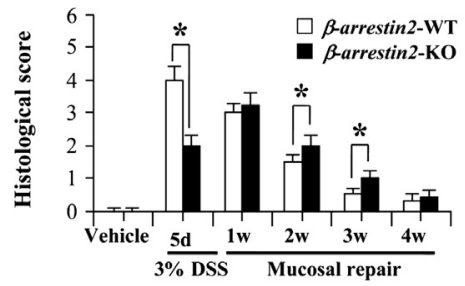

$\mathbf{E}$

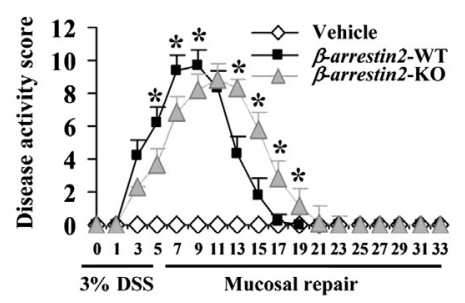

D

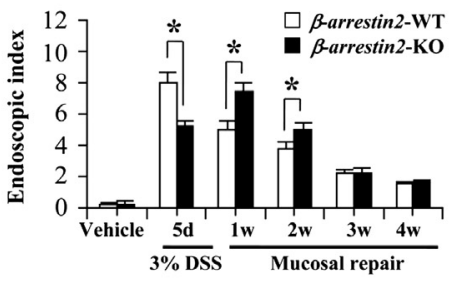

$\mathbf{F}$

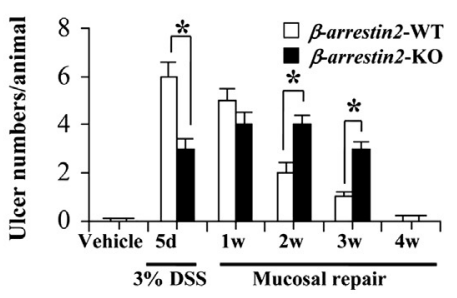

Figure $2 \beta$-Arrestin2 deficiency delays the mucosal repair of experimental colitis in mice. A: Representative photomicrographs of H\&E staining in the colonic sections of WT and $\beta$-arrestin2 KO littermates at indicated time points. B: Colonoscopic images were obtained from WT and $\beta$-arrestin2 KO littermates mice at the indicated time points. C: Histologic scores were determined by analyzing $\mathrm{H \& E}$-stained sections, as described in Materials and Methods. D: Quantitative analysis of the endoscopic index from colonoscopic images. E: The disease activity index was determined at the indicated time points, as described in Materials and Methods. F: Colonic ulcers were counted after methylene blue staining. Data are expressed as means \pm SD. $n=3$ in each group. ${ }^{*} P<0.05$, WT versus $\beta$-arrestin2-K0 mice. Original magnification, $\times 200$. d, day; DSS, dextran sulfate sodium; $\mathrm{H} \& \mathrm{E}$, hematoxylin and eosin; KO, knockout; w, week; WT, wild-type. 
that targeted deletion of $\beta$-arrestin2 delayed the mucosal repair after induction of injury (Figure 2, C, E, and F). Colonoscopic examination and endoscopic index analysis were also used to assess the severity and recovery condition of experimental colitis, and the findings were consistent with those of histologic analysis (Figure 2, B and D). Taken together, we concluded that the absence of $\beta$-arrestin2 delayed epithelial restitution and clearance of inflammation after DSS-induced damage.

\section{$\beta$-Arrestin2 Mediates Mucosal Repair by Promoting Cell Proliferation in Experimental Colitis}

Homeostasis of the gastrointestinal epithelium largely depends on a balance between the proliferation and apoptosis of enterocytes. ${ }^{25,26}$ Current views indicate that abnormal apoptosis in the intestinal epithelial cells contributes to the development of colitis. ${ }^{27,28}$ In the present study, we also confirmed that DSS-induced experimental colitis led to increased apoptosis in intestinal epithelial cells by TUNEL staining (Figure 3A). In agreement with our previous study, ${ }^{5}$ epithelial apoptosis was significantly reduced in $\beta$-arrestin2 KO mice compared with WT mice during the acute injury period. The apoptotic index was suppressed beginning the first week after the cessation of DSS in WT mice. However, during this process, an increased rate of apoptosis was found compared with the injury stage in $\beta$-arrestin $2 \mathrm{KO}$ mice (Figure 3, A and C). The data were consistent with histologic findings that $\beta$-arrestin2 $\mathrm{KO}$ mice had more extensive damage during this early recovery period. This could be one explanation for the early recovery failure in $\beta$-arrestin2 deficiency mice. However, no significant difference was found in the apoptotic index between the two mouse strains during the recovery period (Figure 3, A and C). These results suggest that the impaired mucosal repair is not likely due to increased apoptosis.

Previous research has indicated that hyperproliferation of enterocytes occurred to regenerate injured epithelium from colitis during the recovery stage. ${ }^{29,30}$ By detecting the proliferative marker, Ki-67, we found that $\beta$-arrestin 2 deficiency
A

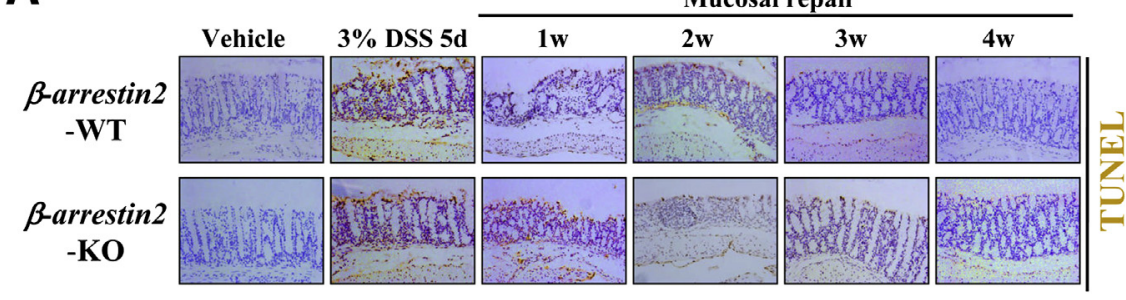

B

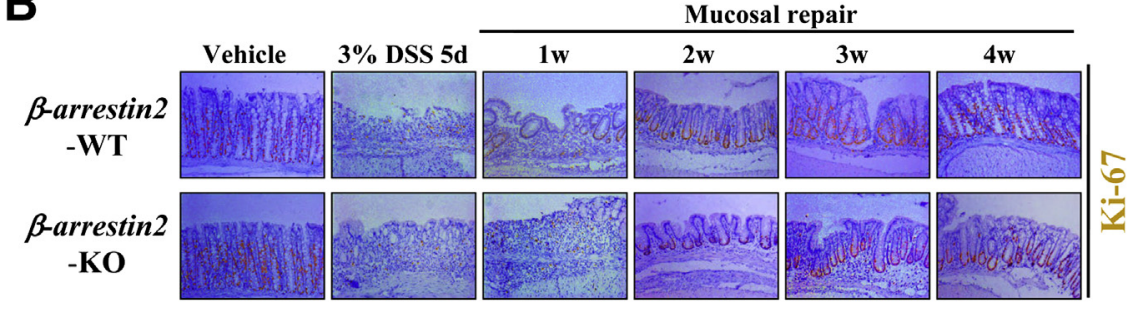

C

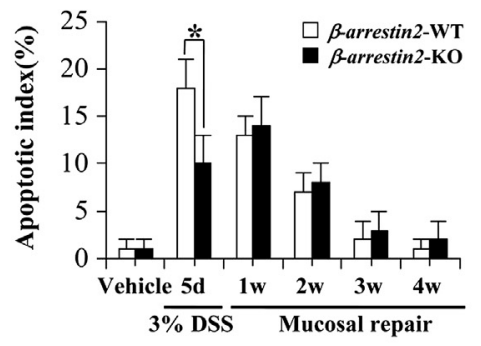

E

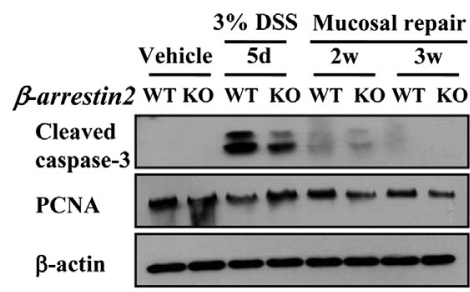

D

$\mathbf{F}$

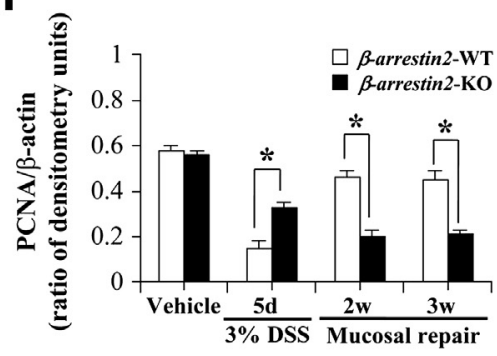

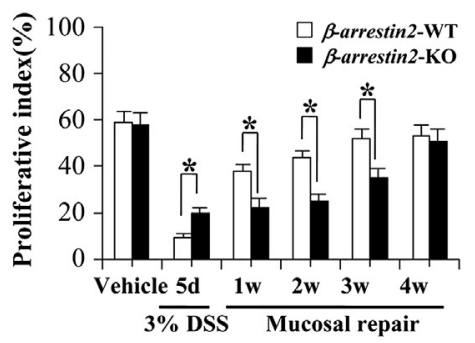

Figure $3 \quad \beta$-Arrestin2-mediated mucosal repair by promoting cell proliferation in experimental colitis. A: Apoptotic cells were detected by TUNEL staining in the colonic sections of WT and $\beta$-arrestin2 KO mice. TUNEL staining reveals apoptotic induction in intestinal epithelial cells (brown). B: Proliferative cells were detected by Ki67 immunohistochemical staining in the colonic sections (brown). C: Apoptotic index was measured by counting TUNEL signals in 100 random fields per section. D: The percentage of $\mathrm{Ki}-67^{+}$cells is represented graphically. E: Western blot analysis for cleaved caspase- 3 and PCNA expression in the colonic mucosa at the indicated time points. $\beta$-Actin served as the loading control. F: Quantitative analysis of PCNA/ $\beta$-actin ratio, as measured by densitometry scanning of Western blot analysis. Data are expressed as means \pm SD. $n=3$ in each group. ${ }^{*} P<0.05$ WT versus $\beta$-arrestin2 $\mathrm{K} 0$ mice. Original magnification, $\times 200$. $d$, day; DSS, dextran sulfate sodium; K0, knockout; PCNA, proliferating cell nuclear antigen; TUNEL, terminal deoxynucleotidyl transferase-mediated dNTP nick-end labeling; w, week; WT, wild-type. 
did not affect basal levels of proliferation in unchallenged mice compared with WT littermates. After DSS administration, a significant decrease was found in the level of proliferation in the two mouse strains. There was also an apparent decrease in $\beta$-arrestin2 $\mathrm{KO}$ mice compared with WT mice. During the recovery period, the proliferative index increased gradually in both types of mice, consistent with crypt regeneration as a component of mucosal repair. ${ }^{31}$ However, WT mice have long, highly proliferative colonic crypts compared with $\beta$-arrestin2 KO mice, which display fewer proliferative cells in shorter crypts (Figure 3B). Quantification of $\mathrm{Ki}-67^{+}$cells found that the proliferation index was obviously higher in WT mice than in $\beta$-arrestin2 $\mathrm{KO}$ mice during the recovery stage (Figure $3 \mathrm{D}$ ). The above-mentioned results were further confirmed by Western blot analysis of activated caspase-3 and PCNA (Figure 3, E and F). Thus, one potential mechanism for the delayed recovery after DSS withdrawal in $\beta$-arrestin2 deficiency mice was due to the impairment of crypt cell proliferation and $\beta$-arrestin2mediated mucosal repair by promoting cell proliferation in experimental colitis.

\section{$\beta$-Arrestin2 Promotes Epithelial and Goblet Cell Regeneration During Mucosal Repair of Experimental Colitis}

The intestinal mucosa can rapidly repair itself by the restitution, proliferation, and differentiation of epithelial cells after damage occurs. ${ }^{32}$ The proliferative compartment of cells is localized in the crypt base which divide to renew themselves and yield more rapidly dividing, transitamplifying progenitor cells that then give rise to the terminally differentiated cells, such as epithelial cells and so on. ${ }^{31}$ Immunostaining for cytokeratin and PAS revealed that targeted deletion of $\beta$-arrestin 2 attenuated the regeneration of epithelial cells and goblet cells during the recovery periods (Figure 4, A and B). These findings further confirmed that $\beta$-arrestin2 deficiency impaired the mucosal recovery as a result of experimental colitis. By quantitative analysis, we found that targeted deletion of $\beta$-arrestin2 delayed the mucosal epithelial and goblet cell repair after induction of injury (Figure 4, C and D).

\section{IGF-1 Is Involved in the Mucosal Repair}

Current views indicate that the repair process in injured epithelium is modulated by a range of growth factors. ${ }^{7-9}$ Several growth factors are secreted locally to stimulate the proliferation of enterocytes. On the basis of the importance of the growth factors in mucosal repair, we quantified the expression of several growth factors in the colon by realtime PCR (Figure 5A and Supplemental Figure S1). We detected relatively higher baseline levels of TGF- $\beta$ and IGF-1 than of EGF and bFGF in WT and $\beta$-arrestin2 KO mice, indicating no apparent difference in the levels of the indicated growth factors between WT and $\beta$-arrestin2 KO
A

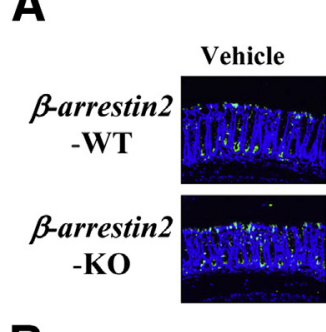
$3 \%$ DSS
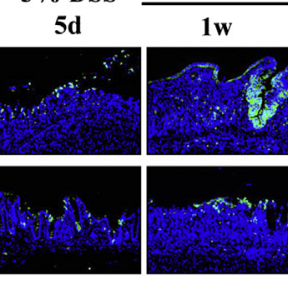

Mucosal repair

B

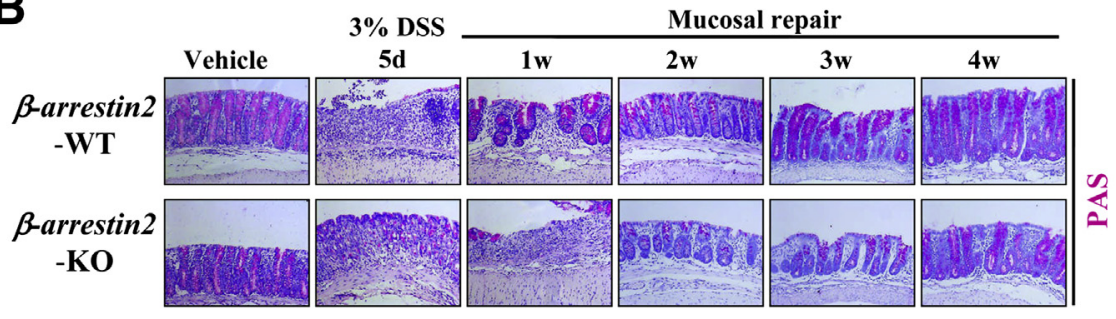

C

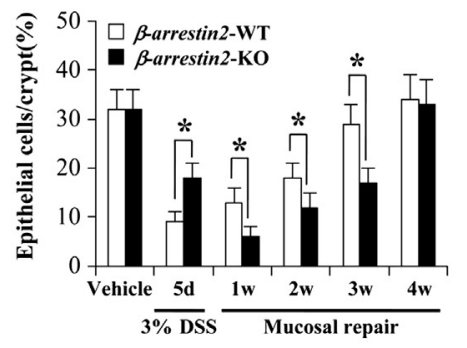

D

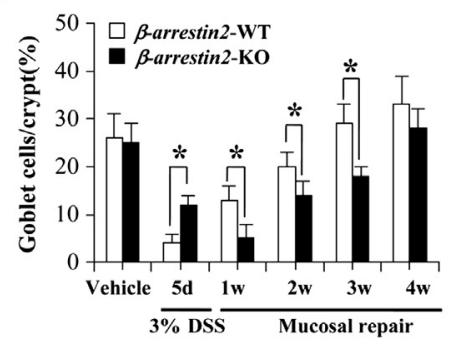

Figure $4 \quad \beta$-Arrestin2 promotes epithelial and goblet cell regeneration during mucosal repair of experimental colitis. A: Immunofluorescence staining for cytokeratin in the indicated colonic sections. Nuclei were stained with DAPI in blue and cytokeratin were stained in green. B: Sections were stained with PAS for goblet cells (pink). C: Quantification of epithelial cells per colonic crypt. D: Goblet cells per colonic crypt were counted as described in Materials and Methods. Data are expressed as means $\pm S D, n=3$ in each group. ${ }^{*} P<0.05 \mathrm{WT}$ versus $\beta$-arrestin2 K0 mice. Original magnification, $\times 200$. $d$, day; DSS, dextran sulfate sodium; KO, knockout; PAS, periodic acid-Schiff; w, week; WT, wild-type. 
mice during the recovery period. However, both the levels of TGF- $\beta$ and IGF-1 increased during the acute and recovery phases. The expression of IGF-1 was the highest among the other growth factors during mucosal repair. These observations are consistent with reports that found up-regulation of IGF-1 in IBD. ${ }^{33-35}$ Previous reports have found that exogenous IGF-1 promotes mucosal healing. ${ }^{11,16,36,37}$ On the basis of this finding, we hypothesized that the increased IGF-1 may participate in the recovery of experimental colitis.

We speculated that the differences in colonic mucosa reparation between the WT and $\beta$-arrestin $2 \mathrm{KO}$ mice may be due to differences in IGF-1 receptor signaling. However, there was no apparent difference in the level of IGF-1 mRNA between the two mouse strains during the recovery period, but a significant difference was found during the acute injury phase (Figure 5B). Moreover, immunostaining and Western blot analysis of p-IGF-1R found almost an identical degree of activation between the two mouse strains during the recovery stage. Nevertheless, no increased IGF-1R activation was found during DSS treatment (Figure 5, C-E, and G). The high concentration of IGF- 1 that failed to activate the receptor may be attributed to the elevated levels of proinflammatory cytokines that induce IGF-1 resistance. ${ }^{38}$ These results indicate that $\beta$-arrestin2 did not affect the secretion of IGF-1 or the activation of IGF-1R.

Immunostaining of $\mathrm{p}-\mathrm{IGF}-1 \mathrm{R}$ found that the increased positive signals were primarily evident in the membranes of goblet cells and epithelial cells (Figure 5, C and E). Therefore, we speculated that IGF-1 promoted repair by regulating the regeneration of goblet cells and epithelial cells. To test our hypothesis, PAS or cytokeratin costaining with p-IGF-1R was performed. The merging signals provided direct evidence that IGF-1 is involved in the mucosal repair by regulating epithelial and goblet cell regeneration (Figure 5, F and H). To summarize, we conclude that IGF-1 contributes to $\beta$-arrestin2-mediated mucosal repair of experimental colitis.

\section{IGF-1 Contributes to the Mucosal Repair of Experimental Colitis by $\beta$-Arrestin2-Mediated ERK Activation}

IGF-1 contributed to $\beta$-arrestin2-mediated mucosal repair of experimental colitis. $\beta$-Arrestin 2 is an important signaling scaffold that facilitates the activation of numerous effectors pathways that regulate cellular proliferation, differentiation, and apoptosis, such as MAPKs and phosphatidylinositol
A

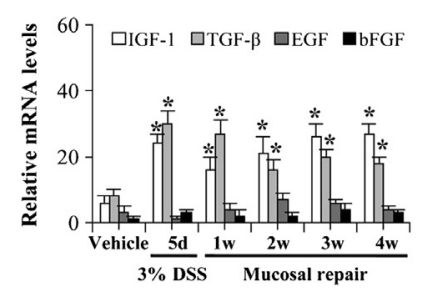

C

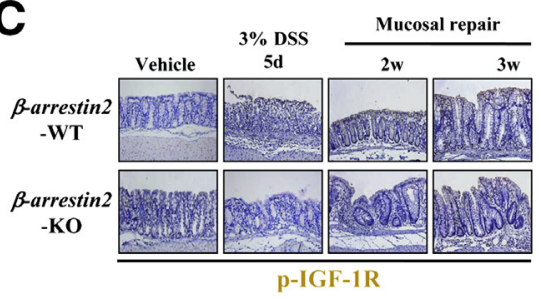

E

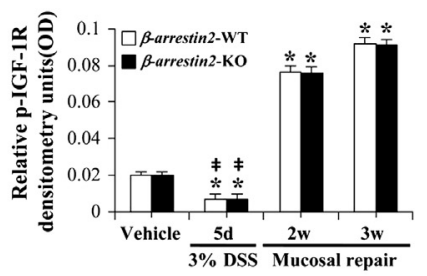

G

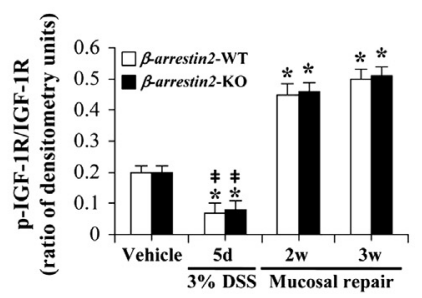

B

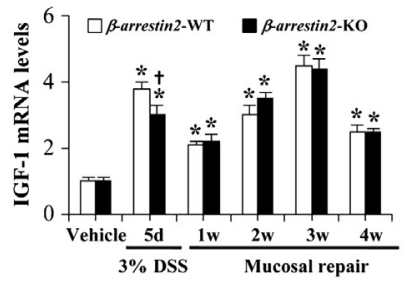

D

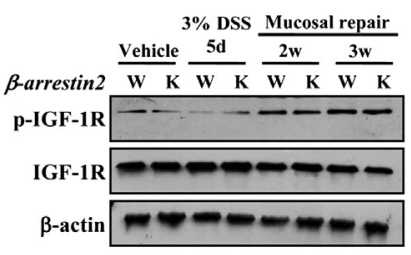

$\mathbf{F}$

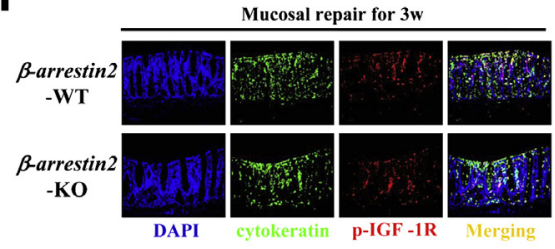

H

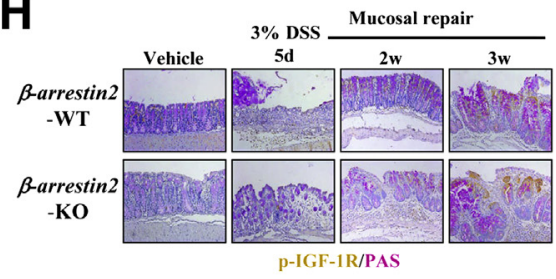

Figure 5 IGF-1 is involved in the mucosal repair. A: The expression of the indicated growth factors in the colonic mucosa of WT mice was evaluated by realtime PCR. B: The relative IGF-1 mRNA level in the colonic mucosa of WT and $\beta$-arrestin2 KO mice. C: Immunohistochemical staining for $\mathrm{p}$-IGF-1R in the indicated colonic sections (brown). D: Representative Western blot analysis for p-IGF-1R and total IGF$1 R$ in the indicated colonic mucosa. $\beta$-Actin served as the loading control. E: Relative p-IGF-1R densitometry units from immunohistochemical staining were represented. F: Double immunofluorescence staining for $\mathrm{p}$-IGF-1R and cytokeratin was performed in the colonic sections after 3 weeks of repair. Nuclei were stained with DAPI in blue. Localization of p-IGF-1R was visualized in red, and cytokeratin was stained in green. The merging positive signals of $\mathrm{p}-\mathrm{IGF}-1 \mathrm{R}$ and cytokeratin were visualized in yellow. G: Quantitative analysis of p-IGF-1R/IGF-1R ratio, as measured by densitometry scanning of Western blot analysis. $\mathbf{H}$ : Costaining of PAS and P-IGF-1R were performed in colonic sections at the indicated time points. Goblet cells were stained in pink, and $\mathrm{p}-\mathrm{IGF}-1 \mathrm{R}$ was visualized in brown. Data are expressed as means \pm SD. $n=3$ in each group. ${ }^{*} P<0.05$ versus scores in vehicle group; ${ }^{\dagger} P<0.05$ WT versus $\beta$-arrestin2-K0 mice; ${ }^{\ddagger} P<0.05$ versus mice from 2 weeks and 3 weeks. Original magnification, $\times 200$. bFGF, basic fibroblast growth factor; d, day; DSS, dextran sulfate sodium; EGF, epidermal growth factor; IGF-1, insulinlike growth factor-1; K0, knockout; OD, optical density; PAS, periodic acid-Schiff; p-IGF-1R, phosphor-IGF-1 receptor; TGF- $\beta$, transforming growth factor $\beta ; w$, week; WT, wild-type. 
3-kinase. The most commonly studied MAPKs are ERK1/2, Jun kinase $1 / 2 / 3$, and p38. ${ }^{39}$ Immunohistochemical staining for active ERK1/2 was also performed to confirm their localization. In both untreated mouse strains, phosphorylated ERK1/2 localized to the differentiated cell lining the surface epithelium, visible as nuclear and diffuse cytoplasm staining throughout the crypt axis during the recovery phase (Figure 6A). Western blot analysis found that $\beta$-arrestin2 deficiency inhibited the activation of ERK1/2 during the recovery phase (Figure 6, B-D). Taken together, the observations suggest that IGF-1 contributed to the mucosal repair of experimental colitis through $\beta$-arrestin2-mediated ERK activity.

\section{IGF-1 Activates $\beta$-Arrestin2/ERK Signaling in Vitro}

To further clarify the findings from the previous section, HCT116 cells were treated with $100 \mathrm{ng} / \mathrm{mL}$ IGF-1 at different time points. IGF-1 treatment led to the induction of $\beta$-arrestin2 in a time-independent manner, provoking a statistically significant stimulation by 1 hour. However, we observed that IGF-1 stimulation resulted in the activation of ERK1/2 in a time-dependent manner, with its plateau starting at 8 hours (Figure 7A and Supplemental Figure S2A). To further address the mechanism involved in this effect, $\beta$-arrestin2 was overexpressed in HCT116 cells by transfection of the pcDNA3.0- $\beta$-arrestin2-GFP plasmid or the pcDNA3.0-GFP vector as the control. IF staining and Western blot analysis confirmed the success of transfection (Figure 7B). Overexpression of $\beta$-arrestin2 did not affect the phosphorylation of IGF-1R in response to IGF-1 treatment; however, IGF-1-induced ERK1/2 activation and PCNA expression were enhanced significantly, which promoted cell proliferation (Figure $7 \mathrm{C}$ ). The specific ERK inhibitor PD98059 not only significantly inhibit the activation of ERK1/2, but it also suppressed cell proliferation by detecting PCNA levels, without affecting the activation of IGF-1R in response to IGF-1 treatment (Figure 7D). We further analyzed cellular proliferation induced by IGF-1 via by using PCNA staining, which found that the proliferative index was significantly increased in response to IGF-1 treatment in cells with overexpression of $\beta$-arrestin2; however, the specific ERK inhibitor PD98059 repressed it as well as in cells transfected with the vector or pcDNA3.0-GFP (Supplemental Figure S2, D and E).

To further confirm the above-mentioned results, the effects of $\beta$-arrestin2 siRNA on IGF-1R signaling were also examined. Transfection of $\beta$-arrestin2 siRNA reduced the level of $\beta$-arrestin2 protein by $49 \%$ compared with nontargeting control siRNA (Figure 7E). Similarly, the phosphorylation of IGF-1R was unaffected by $\beta$-arrestin2 down-regulation. The silencing of $\beta$-arrestin 2 gene expression (Arrb2) markedly attenuated the activation of ERK1/2 and suppressed the proliferation of cells by detecting PCNA expressions (Figure 7F and Supplemental Figure S2, B and C). In summary, these data further found that $\beta$-arrestin2 functioned as an important mediator in ERK activation after IGF-1 stimulation.

\section{Discussion}

Mucosal repair is an important sign of the efficacy of treatment for IBD. Promoting the recovery of mucosa has received growing attention as an alternative approach for the treatment of IBD. ${ }^{2}$ In this study, we uncovered a reparative role for IGF- $1 / \beta$-arrestin2 signaling after DSS-induced experimental colitis. We found that $\beta$-arrestin2 deficiency mice displayed delayed mucosal repair after DSS-induced experimental colitis, most likely by inhibiting cell proliferation. The underlying mechanism is mediated by the absence of $\beta$-arrestin2, which inhibits the activation of the ERK signaling pathway in response to IGF-1.

DSS can produce both acute and chronic UC with features somewhat similar to the symptomatic and histologic
A

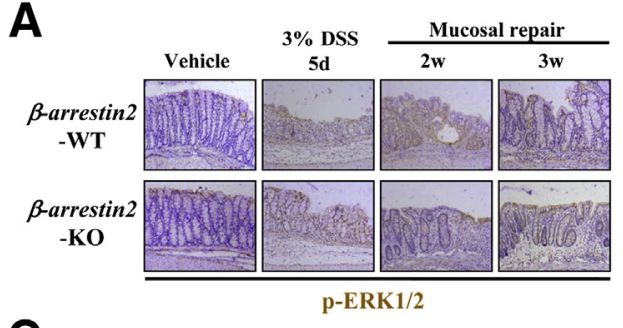

C

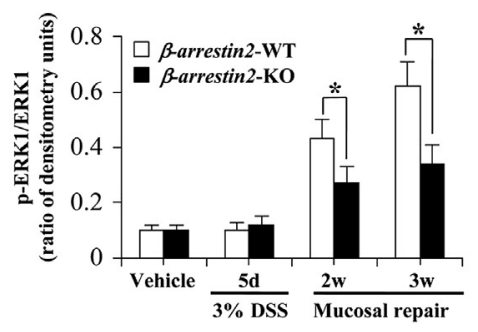

B

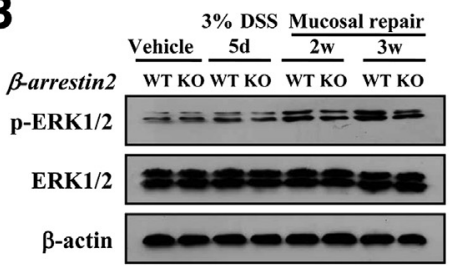

D

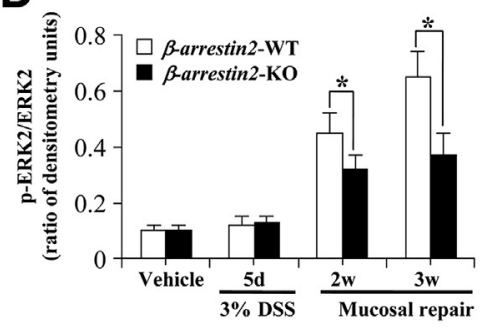

Figure 6 IGF-1 contributes to the mucosal repair of experimental colitis by $\beta$-arrestin2mediated ERK activation. A: Immunohistochemical staining of $p$-ERK1/2 in the colonic sections of WT and $\beta$-arrestin2 $\mathrm{KO}$ mice at the indicated time points (brown). B: Western blot analysis of p-ERK1/2, ERK1/2 in the colonic mucosa of WT and $\beta$-arrestin2 $\mathrm{KO}$ mice at the indicated time points. $\beta$-Actin served as the loading control. C and $\mathbf{D}$ : Quantitative analysis of the p-ERK1/ERK1 and p-ERK2/ERK2 ratios, as measured by densitometry scanning of Western blot analysis. Values are expressed as means $\pm \mathrm{SD}$, ${ }^{*} P<0.05$ WT versus $\beta$-arrestin2 KO mice. Original magnification, $\times 200$. d, day; DSS, dextran sulfate sodium; ERK, extracellular signal-related kinase; IGF-1, insulinlike growth factor-1; K0, knockout; $\mathrm{p}$, phospho; w, week; WT, wild-type. 
A

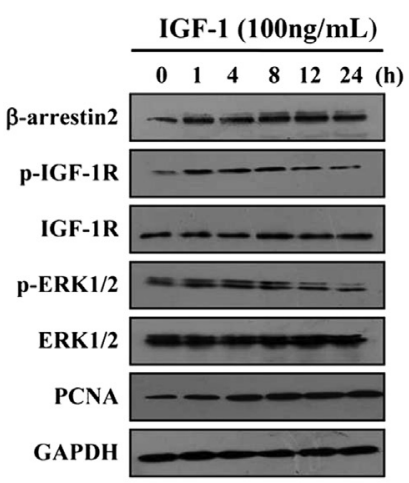

D

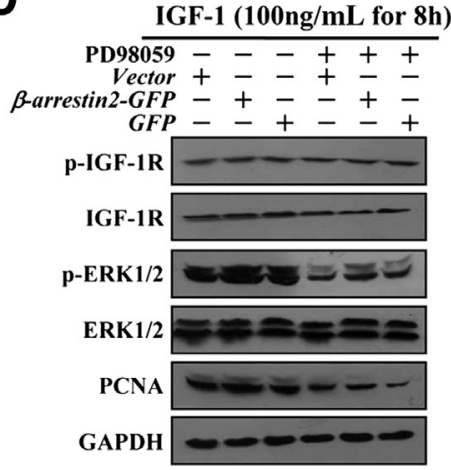

B

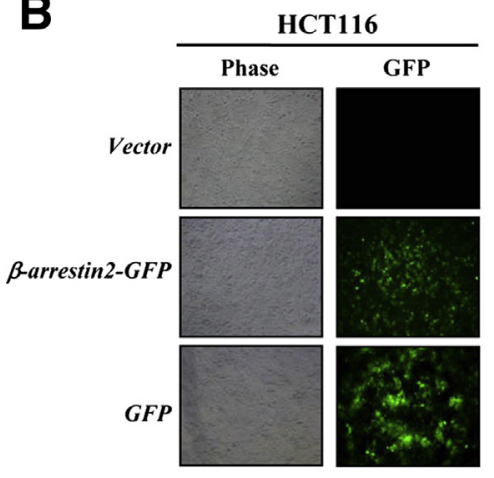

C

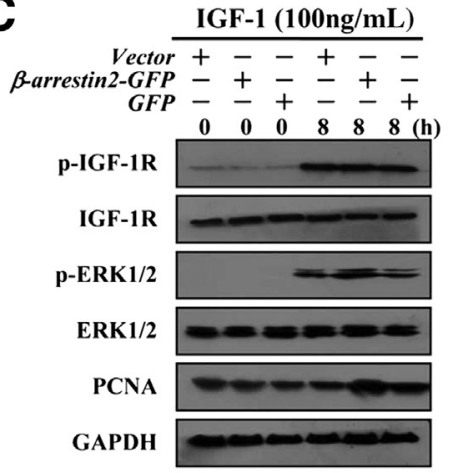

E

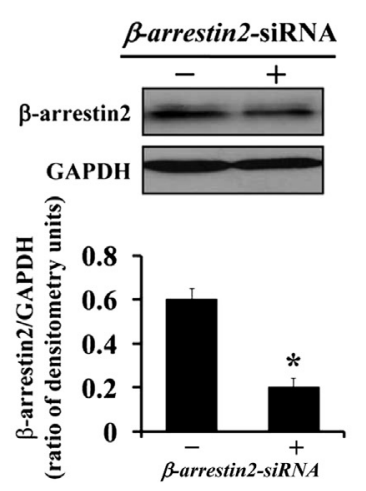

F

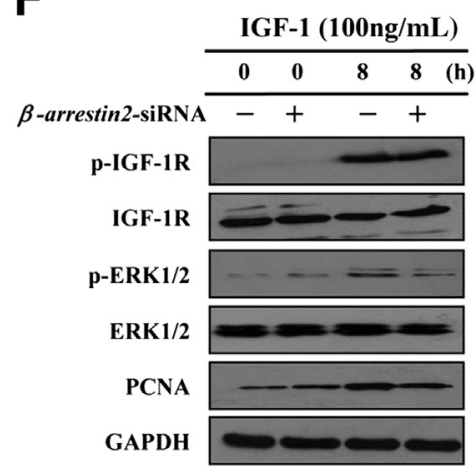

Figure 7 (IGF-1) activates $\beta$-arrestin2/ERK signaling in vitro. A: HCT116 cells were serum-depleted overnight and then stimulated with $100 \mathrm{ng} / \mathrm{mL}$ IGF-1 for the indicated time intervals. The lysates were analyzed for the expression of p-IGF-1R, IGF-1R, $\beta$-arrestin2, p-ERK1/2, and ERK1/2 by Western blot analysis. $\beta$-Actin served as the loading control. B: Immunofluoresence staining and Western blot analysis were used to confirm the efficiency of $\beta$-arrestin2 gene transduction in HCT116 cells. The GFP- $\beta$-arrestin2 was visible at the cytoplasmic membrane. C: HCT116-Vector (Vector), HCT116- $\beta$-arrestin2-GFP ( $\beta$-arrestin2-GFP), and HCT116GFP (GFP) cells were incubated in serum-free medium overnight and then cultured in the presence or absence of $100 \mathrm{ng} / \mathrm{mL}$ IGF- 1 for 8 hours. The lysates were subjected to Western blot analysis for p-IGF-1R, IGF-1R, p-ERK1/2, ERK1/2, and PCNA. GAPDH served as loading control. D: HCT116 cells were stimulated with 100 $\mathrm{ng} / \mathrm{mL}$ IGF-1 for 8 hours in the presence or absence of $20 \mu \mathrm{mol} / \mathrm{L}$ ERK inhibitor PD98059. The lysates were subjected to Western blot analysis for $\mathrm{p}-\mathrm{IGF}-1 \mathrm{R}, \mathrm{IGF}-1 \mathrm{R}, \mathrm{p}-$ ERK1/2, ERK1/2, and PCNA. GAPDH served as a loading control. E: The expression of $\beta$-arrestin2 in HCT116 cells transfected with control siRNA (vector) or $\beta$-arrestin2 siRNA was analyzed by Western blot analysis. Ratio of densitometry units of $\beta$-arrestin2/ $\beta$-actin is shown. F: Effect of IGF- 1 in HCT116 cells transfected with control (vector) or $\beta$-arrestin2 siRNA after the indicated treatments is shown. GAPDH served as the loading control. Data are expressed as means \pm SD. ${ }^{*} P<0.05$ versus control siRNA. Original magnification: $\times 100$ (B). ERK, extracellular signal-related kinase; GAPDH, glyceraldehyde-3-phosphate dehydrogenase; GFP, green fluorescent protein; IGF-1, insulin-like growth factor-1; p-IGF-1R, phospho-IGF-1 receptor; PCNA, proliferating cell nuclear antigen.

findings in humans. ${ }^{23}$ With the use of this model, mice received either water alone or water supplemented with $3 \%$ DSS for 5 days to induce injury, followed by a return to regular drinking water, and they were monitored for an additional 4 weeks to examine the repair process. We discovered that the expression of $\beta$-arrestin 1 and $\beta$-arrestin2 were both up-regulated in the acute phase, but only $\beta$-arrestin2 was induced in the recovery phase. The observations allowed us to interrogate whether the function of $\beta$-arrestin 2 during the recovery stage was different from that during the acute stage. Then we compared the recovery process between WT and $\beta$-arrestin2 KO littermates. Interestingly, the results indicated that mice with $\beta$-arrestin2 deficiency exhibited delayed wound repair at both the clinical and histologic levels. It is interesting that targeted deletion of $\beta$-arrestin2 ameliorated DSS-induced experimental colitis and also resulted in impaired mucosal repair of experimental colitis.

Our previous data represented that the up-regulation of $\beta$ arrestin2 occurred within 24 hours after DSS treatment and could be detected throughout the treatment, and a complete $\beta$-arrestin2 deficiency ameliorated DSS-induced experimental colitis and intestinal mucosal apoptosis in mice. ${ }^{5}$ This sustained $\beta$-arrestin2 induction in acute experimental colitis was a downstream inflammatory response, driven mainly by tumor necrosis factor- $\alpha$, which was widely proven to initiate and perpetuate intestinal inflammation of colitis. ${ }^{5}$ Here, we found that the proinflammatory cytokines such as tumor necrosis factor- $\alpha$ were down-regulated during the repair course, and the induction of $\beta$-arrestin2 promoted mucosal proliferation, mainly mediated by growth factors such as IGF-1 and TGF- $\beta$.

The levels of $\beta$-arrestin 2 were elevated both during the acute and the repair phases, and the targeted deletion of $\beta$-arrestin2 prevented DSS-induced experimental colitis but delayed the mucosal repair in the recovery phases. $\beta$-Arrestin2, as a scaffolding protein that regulates GPCR or non-GPCR signaling, may be involved in various receptormediated signal transduction pathways stimulated by diverse factors during different periods. This novel finding 
warrants the exploration of a much broader role of $\beta$-arrestin2 in cell signaling related to pharmacologic and therapeutic implications in colitis. Increased apoptosis in the epithelium was found at the acute inflammatory sites of UC patients and murine colitis models. ${ }^{27,40}$ Intestinal epithelial cells undergo massive proliferation to reestablish the damaged epithelium during the recovery period. A balance between cellular proliferation and apoptosis is necessary to maintain the integrity of the intestinal barrier. Therefore, we investigated whether impaired recovery in $\beta$-arrestin 2 deficiency mice was due to an imbalance between mucosal apoptosis and proliferation.

Current research indicates that the effect of $\beta$-arrestin2 in apoptosis is still debatable. ${ }^{41-43}$ Although we have found previously that increased $\beta$-arrestin 2 -mediated epithelial cell apoptosis contributes to DSS-induced experimental colitis, ${ }^{5}$ no apparent difference in the apoptotic rate was detected between WT and $\beta$-arrestin2 KO mice during the recovery phase in the present study. The results suggested that the delayed recovery in mice deficient in $\beta$-arrestin 2 was not due to impaired cell survival, and the proapoptotic ability may be counterbalanced or reversed by complex factors during the recovery stage. The precise underlying mechanism of this difference will be revealed in a future study. The proliferation index of crypt cells in WT mice was higher than that in $\beta$-arrestin2 $\mathrm{KO}$ mice during the recovery from experimental colitis, indicating that recovery defect in mice deficient in $\beta$-arrestin 2 was potentially due to the delayed proliferation.

Numerous studies have highlighted the key roles of growth factors in the repair of injured mucosa. IGF-1 possesses the ability to exert insulin-like metabolic activity and to regulate cell proliferation, differentiation, and apoptosis in various cell types and tissues. ${ }^{10,44}$ The majority of IGF-1 is synthesized in the liver; the gastrointestinal tract is also an abundant source of IGF-1. ${ }^{14}$ Previous research has disclosed that local production of IGF-1 in intestines was elevated in IBD. ${ }^{15,16}$ We found that the level of IGF-1 was highest relative to other growth factors during the recovery period in the present study. Most of the cellular actions of IGF-1 are mediated by the binding of the peptides to the IGF-1 receptor. We observed that IGF-1R activation was enhanced by increased IGF-1 levels both in WT and $\beta$-arrestin2 KO mice during the recovery stage. Phosphorylated IGF-1R was generally seen in renewed goblet and epithelial cells. The findings indicate that IGF-1 is involved in the mucosal reparation through promoting $\beta$-arrestin $2-$ mediated goblet and epithelial cell regeneration.

The well-recognized proliferative actions of IGF-1 are largely mediated by phosphatidylinositol 3-kinase/AKT and ERK pathways. ${ }^{13}$ Previous studies have suggested the involvement of $\beta$-arrestins in IGF-1R-mediated AKT and ERK signaling. ${ }^{18,45}$ More in-depth histologic analysis and the obvious impairment of crypt cell proliferation provided quantitative evidence that targeted deletion of $\beta$-arrestin2 delayed the mucosal repair after induction of injury, compared with WT mice. In addition, our results verified that $\beta$-arrestin2 could encourage the phosphorylation of ERK1/2 and cell proliferation in response to IGF-1 in both in vivo and in vitro experiments. Thus, $\beta$-arrestin 2 acted in the downstream of the IGF-1 receptor pathway and the stronger ERK1/2 activation was responsible for the faster recovery; whereas, in $\beta$-arrestin2 KO mice, ERK1/2 signaling was not activated because of a lack of $\beta$-arrestin2 protein modulation during the recovery course, leading to reduced mucosal healing through regulation of its downstream proliferation signaling pathways Thus, IGF-1 contributed to the mucosal repair of experimental colitis mainly by encouraging $\beta$-arrestin2-mediated ERK activation.

A recent study has reported that $\beta$-arrestin1 deficiency almost completely abrogated the development of intestinal inflammation in DSS-induced experimental colitis compared with WT mice, revealing that $\beta$-arrestin1 KO mice were deficient in IL- 6 expression in the colon but had higher expression of the anti-inflammatory IL-10 cytokine family via diminished ERK and NF- $\kappa \mathrm{B}$ pathways in experimental colitis. ${ }^{46}$ Consistent with these interesting observations, our results suggested that $\beta$-arrestin 2 deficiency abrogated the recovery phase after DSS-induced experimental colitis by inhibiting the activation of ERK1/2 in response to IGF-1. However, we did not find altered NF$\kappa \mathrm{B}$ activity or cytokine levels in $\beta$-arrestin2 $\mathrm{KO}$ mice during the acute or recovery period of experimental colitis, compared with WT mice (data not shown). In our study, $\beta$ arrestin1 was only induced in the acute phase but not in the recovery phase of DSS-induced experimental colitis, and $\mathrm{NF}-\kappa \mathrm{B}$ activation and the relative cytokine productions were not affected during this course, which may be related to the different concentrations and time courses of DSS treatment among different experiments; the definite causes need to be explored further.

Current views indicate that GPCR stimulation activates ERK through either $G$ protein- or $\beta$-arrestin2-mediated signaling pathways. ${ }^{4}$ The former activation is rapid and transient, whereas the latter is slower and more persistent. However, $\beta$-arrestin-dependent pathway results in the cytosolic retention of ERK and loss of typical nuclear ERK functions. ${ }^{47,48} \beta$-Arrestin-mediated signaling via ERK was not only mediated by GPCRs but also by tyrosine kinase receptors such as IGF-1/IGF-1R. $\beta$-Arrestin1 recruits Mdm2 to IGF-1R after ligand stimulation, thereby positively mediating ERK activation. $\beta$-Arrestin 2 appears to be more weakly associated with the receptor compared with $\beta$-arrestin1, and $\beta$-arrestin2 does not play an obligatory role in the ERK pathway. ${ }^{18}$

\section{Conclusions}

In summary, our study provides the first evidence that $\beta$-arrestin2 is a critical mediator of mucosal reparation in 
DSS-induced experimental colitis via increased ERK activation in the IGF-1 signaling pathway, and IGF-1 contributes to the mucosal repair of experimental colitis mainly by encouraging $\beta$-arrestin2-mediated ERK activation. The IGF-1/ $\beta$-arrestin2/ERK signaling axis plays an important role in the mucosal repair of experimental colitis. Defining and controlling such biased signaling may provide therapeutic strategies to enhance the mucosal repair of colitis.

\section{Acknowledgments}

We thank Prof. Robert J. Lefkowitz (Duke University Medical Center, Durham, NC) for providing the $\beta$-arrestin2KO mice and the $\beta$-arrestin 2 antibody and Prof. Pei Gang (Tongji University, Shanghai, China) for providing the $\beta$-arrestin2 plasmids.

\section{Supplemental Data}

Supplemental material for this article can be found at http://dx.doi.org/10.1016/j.ajpath.2015.05.020.

\section{References}

1. Xavier RJ, Podolsky DK: Unravelling the pathogenesis of inflammatory bowel disease. Nature 2007, 448:427-434

2. Froslie KF, Jahnsen J, Moum BA, Vatn MH; IBSEN Group: Mucosal healing in inflammatory bowel disease: results from a Norwegian population-based cohort. Gastroenterology 2007, 133:412-422

3. DeWire SM, Ahn S, Lefkowitz RJ, Shenoy SK: Beta-arrestins and cell signaling. Annu Rev Physiol 2007, 69:483-510

4. Kovacs JJ, Hara MR, Davenport CL, Kim J, Lefkowitz RJ: Arrestin development: emerging roles for beta-arrestins in developmental signaling pathways. Dev Cell 2009, 17:443-458

5. Zeng LX, Tao J, Liu HL, Tan SW, Yang YD, Peng XJ, Liu ZH, Jiang J, Wu B: $\beta$-Arrestin2 encourages inflammation-induced epithelial apoptosis through ER stress/PUMA in colitis. Mucosal Immunol 2015, 8:683-695

6. Nusrat A, Delp C, Madara JL: Intestinal epithelial restitution. Characterization of a cell culture model and mapping of cytoskeletal elements in migrating cells. J Clin Invest 1992, 89:1501-1511

7. Theiss AL, Fruchtman S, Lund PK: Growth factors in inflammatory bowel disease: the actions and interactions of growth hormone and insulin-like growth factor-1. Inflamm Bowel Dis 2004, 10:871-880

8. Krishnan K, Arnone B, Buchman A: Intestinal growth factors: potential use in the treatment of inflammatory bowel disease and their role in mucosal healing. Inflamm Bowel Dis 2011, 17:410-422

9. Barahona-Garrido J, Hernandez-Calleros J, Garcia-Juarez I, Yamamoto-Furusho JK: Growth factors as treatment for inflammatory bowel disease: a concise review of the evidence toward their potential clinical utility. Saudi J Gastroenterol 2009, 15:208-212

10. Bortvedt SF, Lund PK: Insulin-like growth factor 1: common mediator of multiple enterotrophic hormones and growth factors. Curr Opin Gastroenterol 2012, 28:89-98

11. Emmerson E, Campbell L, Davies FC, Ross NL, Ashcroft GS, Krust A, Chambon P, Hardman MJ: Insulin-like growth factor-1 promotes wound healing in estrogen-deprived mice: new insights into cutaneous IGF-1R/ERalpha cross talk. J Invest Dermatol 2012, 132:2838-2848

12. Vincent AM, Feldman EL: Control of cell survival by IGF signaling pathways. Growth Horm IGF Res 2002, 12:193-197
13. Chitnis MM, Yuen JS, Protheroe AS, Pollak M, Macaulay VM: The type 1 insulin-like growth factor receptor pathway. Clin Cancer Res 2008, 14:6364-6370

14. Kuemmerle JF: Insulin-like growth factors in the gastrointestinal tract and liver. Endocrinol Metab Clin North Am 2012, 41:409-423

15. Eivindson M, Gronbaek H, Flyvbjerg A, Frystyk J, ZimmermannNielsen E, Dahlerup JF: The insulin-like growth factor (IGF)-system in active ulcerative colitis and Crohn's disease: relations to disease activity and corticosteroid treatment. Growth Horm IGF Res 2007, 17:33-40

16. Howarth GS, Xian CJ, Read LC: Insulin-like growth factor-1 partially attenuates colonic damage in rats with experimental colitis induced by oral dextran sulphate sodium. Scand J Gastroenterol 1998, 33:180-190

17. Lin FT, Daaka Y, Lefkowitz RJ: beta-arrestins regulate mitogenic signaling and clathrin-mediated endocytosis of the insulin-like growth factor 1 receptor. J Biol Chem 1998, 273:31640-31643

18. Girnita L, Shenoy SK, Sehat B, Vasilcanu R, Vasilcanu D, Girnita A, Lefkowitz RJ, Larsson O: Beta-arrestin and Mdm2 mediate IGF-1 receptor-stimulated ERK activation and cell cycle progression. J Biol Chem 2007, 282:11329-11338

19. Sparta A, Baiula M, Campbell G, Spampinato S: beta-Arrestin2 mediated heterologous desensitization of IGF-1R by prolonged exposure of SH-SY5Y neuroblastoma cells to a mu opioid agonist. FEBS Lett 2010, 584:3580-3586

20. Zheng H, Shen H, Oprea I, Worrall C, Stefanescu R, Girnita A, Girnita L: beta-Arrestin-biased agonism as the central mechanism of action for insulin-like growth factor 1 receptor-targeting antibodies in Ewing's sarcoma. Proc Natl Acad Sci U S A 2012, 109:20620-20625

21. Qiu W, Wu B, Wang X, Buchanan ME, Regueiro MD, Hartman DJ, Schoen RE, Yu J, Zhang L: PUMA-mediated intestinal epithelial apoptosis contributes to ulcerative colitis in humans and mice. J Clin Invest 2011, 121:1722-1732

22. Becker C, Fantini MC, Neurath MF: High resolution colonoscopy in live mice. Nat Protoc 2006, 1:2900-2904

23. Low D, Nguyen DD, Mizoguchi E: Animal models of ulcerative colitis and their application in drug research. Drug Des Devel Ther 2013, 7 : 1341-1357

24. Melgar S, Karlsson A, Michaelsson E: Acute colitis induced by dextran sulfate sodium progresses to chronicity in C57BL/6 but not in BALB/c mice: correlation between symptoms and inflammation. Am J Physiol Gastrointest Liver Physiol 2005, 288:G1328-G1338

25. Hall PA, Coates PJ, Ansari B, Hopwood D: Regulation of cell number in the mammalian gastrointestinal tract: the importance of apoptosis. J Cell Sci 1994, 107:3569-3577

26. Maloy KJ, Powrie F: Intestinal homeostasis and its breakdown in inflammatory bowel disease. Nature 2011, 474:298-306

27. Iwamoto M, Koji T, Makiyama K, Kobayashi N, Nakane PK: Apoptosis of crypt epithelial cells in ulcerative colitis. J Pathol 1996, 180:152-159

28. Edelblum KL, Yan F, Yamaoka T, Polk DB: Regulation of apoptosis during homeostasis and disease in the intestinal epithelium. Inflamm Bowel Dis 2006, 12:413-424

29. Fukata M, Chen A, Klepper A, Krishnareddy S, Vamadevan AS, Thomas LS, Xu R, Inoue H, Arditi M, Dannenberg AJ, Abreu MT: Cox-2 is regulated by Toll-like receptor-4 (TLR4) signaling: role in proliferation and apoptosis in the intestine. Gastroenterology 2006, 131:862-877

30. Edelblum KL, Washington MK, Koyama T, Robine S, Baccarini M, Polk DB: Raf protects against colitis by promoting mouse colon epithelial cell survival through NF-kappaB. Gastroenterology 2008, 135:539-551

31. Okamoto R, Watanabe M: Cellular and molecular mechanisms of the epithelial repair in IBD. Dig Dis Sci 2005, 50:S34-S38

32. Sturm A, Dignass AU: Epithelial restitution and wound healing in inflammatory bowel disease. World J Gastroenterol 2008, 14:348-353

33. Zeeh JM, Hoffmann P, Sottili M, Eysselein VE, McRoberts JA: Upregulation of insulin like growth factor 1 binding sites in experimental colitis in rats. Gastroenterology 1995, 108:644-652 
34. Flynn RS, Murthy KS, Grider JR, Kellum JM, Kuemmerle JF: Endogenous IGF-1 and alphaVbeta3 integrin ligands regulate increased smooth muscle hyperplasia in stricturing Crohn's disease. Gastroenterology 2010, 138:285-293

35. Thomas AG, Holly JM, Taylor F, Miller V: Insulin like growth factor1 , insulin like growth factor binding protein-1, and insulin in childhood Crohn's disease. Gut 1993, 34:944-947

36. Williams KL, Fuller CR, Dieleman LA, DaCosta CM, Haldeman KM, Sartor RB, Lund PK: Enhanced survival and mucosal repair after dextran sodium sulfate-induced colitis in transgenic mice that overexpress growth hormone. Gastroenterology 2001, 120:925-937

37. Rijcken E, Fuchs $\mathrm{T}$, Sachs L, Kersting CM, Bruewer M, Krieglstein CF: Insulin-like growth factor 1-coated sutures improve anastomotic healing in an experimental model of colitis. Br J Surg 2010, 97:258-265

38. O'Connor JC, McCusker RH, Strle K, Johnson RW, Dantzer R, Kelley KW: Regulation of IGF-1 function by proinflammatory cytokines: at the interface of immunology and endocrinology. Cell Immunol 2008, 252:91-110

39. Lefkowitz RJ, Shenoy SK: Transduction of receptor signals by betaarrestins. Science 2005, 308:512-517

40. Hagiwara C, Tanaka M, Kudo H: Increase in colorectal epithelial apoptotic cells in patients with ulcerative colitis ultimately requiring surgery. J Gastroenterol Hepatol 2002, 17:758-764

41. Yu MC, Su LL, Zou L, Liu Y, Wu N, Kong L, Zhuang ZH, Sun L, Liu HP, Hu JH, Li D, Strominger JL, Zang JW, Pei G, Ge BX: An essential function for beta-arrestin2 in the inhibitory signaling of natural killer cells. Nat Immunol 2008, 9:898-907

42. Witherow DS, Garrison TR, Miller WE, Lefkowitz RJ: beta-Arrestin inhibits NF-kappaB activity by means of its interaction with the NF-kappaB inhibitor IkappaBalpha. Proc Natl Acad Sci U S A 2004, 101:8603-8607

43. Ahn S, Kim J, Hara MR, Ren XR, Lefkowitz RJ: beta-Arrestin2 mediates anti-apoptotic signaling through regulation of BAD phosphorylation. J Biol Chem 2009, 284:8855-8865

44. Lund PK, Zimmermann EM: Insulin-like growth factors and inflammatory bowel disease. Baillieres Clin Gastroenterol 1996, 10:83-96

45. Povsic TJ, Kohout TA, Lefkowitz RJ: Beta-arrestin1 mediates insulin-like growth factor 1 (IGF-1) activation of phosphatidylinositol 3-kinase (PI3K) and anti-apoptosis. J Biol Chem 2003, 278: 51334-51339

46. Lee T, Lee E, Irwin R, Lucas PC, McCabe LR, Parameswaran N: $\beta$ arrestin-1 deficiency protects mice from experimental colitis. Am J Pathol 2013, 182:1114-1123

47. Tohgo A, Pierce KL, Choy EW, Lefkowitz RJ, Luttrell LM: betaArrestin scaffolding of the ERK cascade enhances cytosolic ERK activity but inhibits ERK-mediated transcription following angiotensin AT1a receptor stimulation. J Biol Chem 2002, 277:9429-9436

48. Luttrell LM, Roudabush FL, Choy EW, Miller WE, Field ME, Pierce KL, Lefkowitz RJ: Activation and targeting of extracellular signal-regulated kinases by beta-arrestin scaffolds. Proc Natl Acad Sci U S A 2001, 98:2449-2454 